\title{
REALIZAÇÕES DOS FONEMAS /d/ E / t/ NOS MUNICÍPIOS DE ARARI E PINHEIRO: UMA ABORDAGEM GEOLINGUÍSTICA
}

\author{
Georgiana Márcia Oliveira Santos* \\ Francimone da Graça Barros Dutra ${ }^{* *}$
}

RESUMO: Este trabalho objetivou-se investigar as realizações dos fonemas /d/ e / t/ diante de [i, $\mathrm{I}]$ nos municípios maranhenses de Arari e Pinheiro, visando a ratificar a não palatalização que, historicamente, particulariza o português falado nesses municípios. A pesquisa baseou-se em Aguilera; Altino, 2012, Aragão, 2018, Cagliari, 1974, Cardoso, 2010, Silva, 2002. Realizaram-se pesquisas de campo para a coleta dos dados, transcrição fonética e grafemática, elaboração de cartas linguísticas, análise dos dados. A análise apontou que a não palatalização, nessas localidades, já não é tão recorrente como dita historicamente.

PALAVRAS-CHAVE: Fonemas; Geolinguística; Não palatalização.

\section{Introdução}

A variação linguística é um fenômeno inerente a todas as línguas. Assim, o Português Brasileiro, doravante (PB), apresenta diferenças internas em função das distintas localidades de origem dos falantes no território nacional, entre tantos outros fatores.

Temos, por exemplo, a realização não palatalizada dos fonemas /d/ e /t/ na fala de maranhenses naturais de alguns municípios da microrregião da Baixada Maranhense. Isso foi o que nos motivou a investigar o português falado nos municípios de Arari e de Pinheiro, historicamente, marcado pela não palatalização.

Este artigo tem como objetivo geral investigar as realizações dos fonemas /d/ e /t/ diante de [i, I], nos municípios maranhenses de Arari e de Pinheiro, com o intuito de

\footnotetext{
* Professora do Departamento de Letras da Universidade Federal do Maranhão (Ufma). Professora Permanente do Programa de Pós-Graduação em Letras (PPGLetras) da Ufma. Coordenadora do Grupo de Estudos e Pesquisas em Línguas, Memórias, Identidades e Culturas (GELMIC). Pesquisadora permanente do Projeto Atlas Linguístico do Maranhão (ALiMA).

** Mestranda em Letras pela Universidade Federal do Maranhão (Ufma). Professora da rede estadual de educação do Maranhão. Pesquisadora associada do Grupo de Estudos e Pesquisas em Línguas, Memórias, Identidades e Culturas (GELMIC).
} 
confirmar ou refutar a não palatalização tida como característica desses municípios. Consonante a esse propósito, estabelecemos como objetivos específicos: i) identificar os fatores extralinguísticos responsáveis pela realização desse fenômeno nessas localidades e ii) fornecer informações que contribuam para a sistematização descritiva das particularidades do português falado na Baixada Maranhense, de forma especial, nos municípios de Arari e de Pinheiro.

Sobre o suporte teórico, realizamos uma discussão sobre o fenômeno da não palatalização e da palatalização dos fonemas consonantais / d/ e /t/ no português brasileiro, com considerações sobre fonemas e alofones, a partir, especialmente, dos estudos sobre Fonética e Fonologia feitos por Silva (2002) e sobre não palatalização e palatalização desenvolvidos por Cagliari (1974) e Aragão (2018). Pautamo-nos, também, nos estudos sobre a Dialetologia e Geolinguística desenvolvidos, sobretudo, por Cardoso (2010), Aguilera; Altino (2012), dentre outros.

Metodologicamente, seguiram-se os critérios de seleção de informantes do Atlas Linguístico do Maranhão (ALiMA), realizaram-se pesquisas de campo para a coleta de dados do município de Arari; transcrição fonética e grafemática; revisão da transcrição fonética e grafemática dos dados de Pinheiro, coletados e transcritos pela equipe do Projeto ALiMA; elaboração de cartas linguísticas; análise dos dados resultantes da aplicação de 18 questões previamente selecionadas do Questionário Fonético-Fonológico (QFFF) do ALiMA.

Ressaltamos que a realização deste trabalho é de suma importância, pois tem a finalidade de colaborar para a ampliação do conhecimento da variedade maranhense do Português falado na Baixada Maranhense, e, mais especificamente, para a ampliação e aprofundamento dos estudos sobre os fatores de não palatalização que marcam o PB falado no Maranhão. Sua relevância afirma-se, ainda, pela possibilidade de contribuir com os estudos sobre as áreas dialetais do Maranhão e com o combate ao preconceito linguístico em relação à fala da Baixada no estado.

A estrutura deste artigo é composta, além da introdução, por quatro seções: fundamentação teórica, procedimentos metodológicos, análise de resultados e considerações finais.

\section{O fenômeno da não palatalização e da palatalização dos fonemas consonantais /d/ e} $/ \mathrm{t} /$

A não palatalização é um fenômeno linguístico que vem sendo estudado na área da linguística descritiva. O que, diretamente, proporciona a ocorrência ou não da não palatalização é a produção dos sons. 
É importante entendermos que fonema é a unidade sonora que se difere funcionalmente das outras unidades da língua (SILVA, 2002). Como exemplo, temos as palavras dia e tia que apresentam uma oposição distintiva nas primeiras unidades sonoras, ou seja, nos fonemas iniciais. Já as possíveis realizações associadas a um mesmo fonema chamamos de alofone. Assim, foneticamente, as duas palavras exemplificadas acima podem ser pronunciadas ['die] e ['tie] ou ['dzie] e ['t $f i e]$. Considerando isso, enfatizamos que os fenômenos investigados neste trabalho são alofônicos, ou seja, [d] e [dz], como alofones do fonema /d/, e [t] e $[\mathrm{t}]$ como alofones do fonema $/ \mathrm{t} /$.

Verificamos que os sons [d3] e [t]] ocorrem antes dos fones [i, I], como se vê em dia, índio, tarde, tia, mentira, tomate, etc. Portanto, interpretamos [d3] e [t $\mathrm{f}]$ apenas como alofones condicionados, nesta pesquisa, pelos contextos $[\mathrm{i}, \mathrm{I}]$.

Conforme afirma Lopes (2001), podemos dizer que as realizações [d] e [t] diante de [i, I] são, quanto ao modo de articulação, oclusivos, pois são resultantes do bloqueamento total, mas sempre momentâneo, da corrente de ar em alguma parte da boca. Em relação ao ponto de articulação, ambos são classificados como linguodentais ou apicodentais, pois há o contato do ápice da língua com os dentes superiores (LOPES, 2001).

No PB, os fonemas /d/ e /t/, nos contextos já mencionados, são pronunciados como linguopalatais, como em ['dzie e ['tfie], na maior parte do Brasil. É possível observarmos, todavia, que, em alguns estados brasileiros, sobretudo da região Nordeste, como a Paraíba, Pernambuco, Maranhão (em especial, os municípios de Arari e Pinheiro - localidades de inquérito da nossa pesquisa), os falantes pronunciam os respectivos fonemas como linguodentais, ou seja, de forma não palatalizada. Ilari e Basso (2007) ressaltam que o caráter regional das variedades do PB é marcado, entre outros traços de pronúncia, pela ausência da palatalização de /d/ e /t/. Para os referidos autores,

\footnotetext{
A palatização (pronunciados ['dent $\left.\int \mathrm{I}\right]$, [pra'tfinhu], ['dzisku] é fenômeno generalizado em todo o território brasileiro, com exceção do interior de São Paulo e da região Sul (pronunciado ['lejte 'kẽte]; encontrado também em regiões de Pernambuco, do Ceará, do Maranhão e do Piauî)". (ILARI; BASSO, 2007. p. 168).
}

Diante disso, ressaltamos que o processo de palatalização pelo qual passam os fonemas consonantais /d/ e /t/, de acordo com o que afirma Silva (2002, p. 35), "consiste no levantamento da língua em direção à parte posterior do palato duro, ou seja, a língua direciona-se para uma posição anterior, mais para a frente da cavidade bucal do que normalmente ocorre quando se articula um determinado segmento consonantal". 
No que diz respeito à não palatalização, Aragão (2018, p. 2) a concebe como a "perda de traço palatal na articulação de um fonema, [a qual] pode ser vista também como variedade regional, social, estilística ou individual."

Bergo (1986), por sua vez, descreve a não palatalização como sendo "um fenômeno fonético que consiste em substituir um fonema palatal por um fonema alveolar ou linguodental em razão de não se apoiar devidamente a ponta da língua na abóbada palatina ao proferir o determinado som". Cagliari (1974) se refere a esse fenômeno fonético como uma etapa da evolução do som palatal e afirma que o fenômeno se dá por meio do enfraquecimento do contato linguopalatal.

Historicamente, se afirma que os alofones [d3] e [t $\mathrm{f}]$ são realizados em boa parte do estado do Maranhão, ou seja, uma parte considerável dos maranhenses realiza os fonemas /d/ e / $\mathrm{t}$ / de forma palatalizada, e uma outra parte, mais concentrada na Baixada Maranhense, como nos municípios de Arari e Pinheiro, realiza-os de forma não palatalizada: [d] e [t]. Nesse sentido, questionamos quais fatores ocasionam essa variação no Maranhão.

\section{Dialetologia e Geolinguística}

Conforme registrado no dicionário de Dubois (1978, p. 185), a Dialetologia é “a disciplina que assumiu a tarefa de descrever comparativamente os diferentes sistemas dialetais em que uma língua se diversifica no espaço, e de estabelecer-lhes os limites”. Assim, podemos dizer que o foco da Dialetologia é o estudo das falas regionais e, com isso, relacionam-se a língua e o espaço geográfico.

Os estudos dialetológicos, de acordo com o que afirma Costa (2012, p. 3), descrevem "as características próprias da linguagem utilizada em determinadas regiões, com o propósito de identificar áreas dialetais mais ou menos coesas".

Nesse sentido, ressaltamos que os estudos dialetológicos contemporâneos levam em consideração também

as variações verticais, ocorrendo uma inserção dos preceitos metodológicos da sociolinguística nas pesquisas de cunho dialetal que passam a considerar dados de ordem social em conjunto com a visão diatópica da língua. Assim é que os trabalhos geolinguísticos começam a fazer o controle sistemático de algumas variáveis como escolaridade, faixa etária e gênero do informante. (COSTA, 2012. p. 2).

Nesse contexto, deve-se entender a Geolinguística como um método utilizado pela Dialetologia. Esse método é, segundo Dubois (1978, p. 307), “o estudo das variações na utilização da língua por indivíduos ou grupos sociais de origens geográficas diferentes".

Coseriu (1987, p. 79), por sua vez, discorre que a Geolinguística 
Designa exclusivamente um método dialetológico e comparativo [...] que pressupõe o registro em mapas especiais de um número relativamente elevado de formas lingüísticas (fônicas, lexicais ou gramaticais) comprovadas mediante pesquisa direta e unitária numa rede de pontos de um determinado território, ou que, pelo menos, tem em conta a distribuição das formas no espaço geográfico correspondente à língua, às línguas, aos dialetos ou aos falares estudados (COSERIU, 1987. p. 79).

É válido considerarmos, ainda, o posicionamento de Cardoso (2010, p. 67), visto que a referida autora afirma que "a geolinguística deve continuar a priorizar a variação diatópica, sem a busca obcecante da quantificação, mas tomando-a de forma exemplificativa e não exaustiva, de modo a complementar os próprios dados reais". A autora ainda destaca a importância das pesquisas geolingüísticas quando afirma:

Se as diferenças espaciais ganham destaque em relação às demais é porque, na realidade dos fatos, as evidências de aproximação ou distanciamento dos fenômenos assumem expressão de maior nitidez e de mais fácil percepção nos espaços físicos, portanto geográficos. Tal visão conduziu a que os estudos geolinguísticos aflorassem em todos os continentes e apresentassem um continuado e crescente desenvolvimento, o que explica a expansão de projetos que levaram à construção de atlas linguísticos com diferenciadas visões espaciais. (CARDOSO, 2010. p. 47).

No Brasil, os estudos dialetológicos, de acordo com Cardoso (1997, p. 2), visam a descortinar os traços linguísticos deste país. Assim, para a referida autora, a Dialetologia

propõe-se a investigar os aspectos variáveis do sistema linguístico, principalmente os que dizem respeito à variação geográfica, e bem antes das pesquisas sociolinguísticas, já se preocupava em demonstrar que a língua é um sistema variável devido a fatores diastráticos, diafásicos e diatópicos, assumindo que tais variações podem determinar a mudança da língua (CARDOSO, 1997. p. 2).

Esses estudos dialetológicos iniciaram-se no final do século XIX e início do XX e tiveram algumas fases, cada qual com as características que as identificam. Em relação aos estudos dialetais brasileiros, Mota e Cardoso (2006) propõem quatro fases: na primeira, predominam obras de caráter lexicográfico; na segunda, sobressaem-se as obras de caráter monográfico; na terceira, há o surgimento de trabalhos geolinguísticos, como elaboração de atlas de diferentes estados; na quarta fase, temos os trabalhos dialetais desenvolvidos a partir do momento em que o Projeto Atlas Linguístico do Brasil - ALiB foi iniciado.

Conforme apresenta Romano (2013, p. 145), a partir da década de 60, no âmbito dos estudos e pesquisas geolinguísticas foram consideradas novas orientações, uma vez que "passaram a inserir alguns pressupostos metodológicos da Sociolinguística, agregando à variável diatópica, variáveis sociais". Isso vem possibilitando que se entenda de forma mais ampla e coerente muitos fenômenos relacionados à variação linguística, pois são indiscutíveis "a 
importância e a necessidade de associar dados diastráticos, diagenéricos ${ }^{1}$, diageracionais, diarreferenciais e diamésicos aos dados diatópicos da Geolinguística iniciada por Wenker e Gilliéron, no final do século XIX.” (AGUILERA; ALTINO, 2012, p. 871).

Dessa forma, Cardoso (2016, p. 5) reitera que os fatores de cunho social, por exemplo, a profissão, o sexo, a escolaridade, a idade "têm-se constituído em aspectos da variação que, de forma diferenciada e com graus distintos de focalização, vêm ocupando lugar nos estudos dialetais, especificamente, naqueles que se desenvolvem sob a metodologia geolingüística".

Destacamos, assim, que a inserção das variáveis sociais na formação do corpus dos atlas linguísticos estaduais brasileiros, como o Atlas Linguístico do Maranhão - ALiMA, revela informações significativas das particularidades do sistema dialetal do país.

\section{Locus e corpus da pesquisa}

O corpus deste trabalho é proveniente da pesquisa de campo feita com os informantes naturais de Arari e da coleta de dados realizada pela equipe de inquiridores do ALiMA em Pinheiro.

É pertinente esclarecermos que o projeto ALiMA apoia-se em procedimentos metodológicos da geografia linguística, método por excelência da Dialetologia, e se insere na categoria dos atlas linguísticos de terceira geração (cf. CARDOSO, 2010). O Projeto conta com uma rede de pontos linguísticos formada por 16 municípios maranhenses ${ }^{2}$.

No total, o projeto ALiMA teve 68 informantes que atenderam ao seguinte perfil: pessoas de ambos os sexos, nascidas e criadas nas localidades investigadas, distribuídas equitativamente em duas faixas etárias - 18 a 30 anos e 50 a 65 anos - e de dois níveis de escolaridade - apenas fundamental (incompleto), nas localidades do interior, e fundamental (incompleto) e superior, nas capitais. Destacamos que para a realização da pesquisa no município de Arari, utilizamos a mesma metodologia adotada por esse referido projeto.

Os municípios Arari e Pinheiro, alvos da nossa investigação sobre a não palatalização dos fonemas /d/ e /t/, fazem parte da microrregião da Baixada Maranhense, a qual se localiza na região do entorno do Golfão Maranhense.

\footnotetext{
${ }^{1}$ Em nosso trabalho, adotamos o termo diassexual.

${ }^{2}$ Inicialmente, foram selecionados 18 municípios para compor a rede de pontos do ALiMA. Entretanto, no decorrer da pesquisa, a coordenação do ALiMA decidiu excluir duas localidades - Maracaçumé (MA06), porque já estava incluso na região compreendida por Turiaçu, e Santa Luzia (MA15), por se tratar de um município mais novo, criado com o desmembramento de Pindaré-Mirim, espaço geográfico já contemplado pelo ponto MA16, correspondente a Bacabal.
} 
Arari possui população de 28.488 habitantes, conforme o Censo de 2010, mas, de acordo com atualização em 2016, sua população é estimada em 29.297 habitantes, fica distante $162 \mathrm{~km}$ da capital do Maranhão. Sua denominação vem do tupi-guarani e significa arara pequena. Arari foi fundado por um padre jesuíta português, chamado José da Cunha D’Eça, foi desmembrado de Vitória do Baixo Mearim e elevado à categoria de município pela lei provincial no 690, de 27/06/1864. Embora esse município não tenha uma grande estrutura, vem crescendo no aspecto econômico e cultural do estado graças às festas religiosas e ao fenômeno da Pororoca. (PREFEITURA DE ARARI, 2017)

Pinheiro é um município que tem aproximadamente 82.000 habitantes, segundo estimativa prevista do IBGE para o ano 2017, e área de $1.559 \mathrm{~km}^{2}$. Teve origem a partir de uma fazenda que foi fundada pelo Capitão-mor Inácio José Pinheiro, em 1819, que estava em busca de alternativas que atendessem às necessidades do seu rebanho, pois, em Alcântara, onde estava, havia pouca pastagem para o gado. (CARDOSO, 2001). De acordo com o referido autor, a chegada de novos fazendeiros movimentou a atividade pecuária e se iniciou um pequeno povoado nos campos do Rio Pericumã.

No ano de 1885, passou a distrito com a denominação de Pinheiro, pela lei provincial $n^{\circ} 370$, de 26 de maio, subordinado ao município de Guimarães. Elevado à categoria de Vila com a denominação de Pinheiro, pela lei provincial no 439, de 03 de setembro de 1856, desmembrado de Guimarães. (BIBLIOTECA ONLINE-IBGE/SA)

\section{Perfil dos informantes}

Para a delimitação do perfil e codificação dos informantes que compuseram nosso corpus coletado em Arari, e observando as questões éticas, seguimos o mesmo padrão adotado pelo ALiMA.

Desse modo, nossa amostra de Arari está composta por oito inquéritos realizados com pessoas de ambos os sexos, nascidas e criadas na localidade investigada, distribuídas equitativamente em duas faixas etárias -18 a 30 anos e 50 a 65 anos e que tenham apenas o nível fundamental (incompleto).

No Quadro 1, podemos verificar a distribuição dos informantes em cada um dos municípios segundo os critérios de perfil estabelecidos. Sobre os códigos utilizados, na coluna Código do Informante, as letras iniciais correspondem à sigla do Estado, seguida pelo número atribuído à localidade (MA 3 refere-se a Pinheiro e MA 19 refere-se a Arari), separado por uma barra diagonal com o número que representa o perfil do entrevistado: 1 e 2 , referem-se aos entrevistados da faixa etária I (FI) que têm entre 18 e 30 anos, e 3 e 4, aos da faixa etária 
II (FII) que têm entre 50 e 65 anos. Os números ímpares indicam o sexo masculino e os pares, o feminino. Todos os informantes possuem apenas o Ensino Fundamental (EF).

Quadro 1 - Perfil dos informantes deste estudo

\begin{tabular}{|l|c|c|c|l|}
\hline \multicolumn{1}{|c|}{ LOCALIDADE } & $\begin{array}{c}\text { CÓD. } \\
\text { DO INFOR. }\end{array}$ & $\begin{array}{c}\text { FAIXA } \\
\text { ETÁRIA/IDADE }\end{array}$ & $\begin{array}{c}\text { ESCOLARI- } \\
\text { DADE }\end{array}$ & \multicolumn{1}{|c|}{ SEXO } \\
\hline \multirow{3}{*}{$\begin{array}{l}\text { MA 3 } \\
\text { (Pinheiro) }\end{array}$} & $\mathrm{MA3/1}$ & FI & EF & Masculino \\
\cline { 2 - 5 } & $\mathrm{MA3/2}$ & FI & EF & Feminino \\
\cline { 2 - 5 } & $\mathrm{MA3/3}$ & FII & EF & Masculino \\
\cline { 2 - 5 } & $\mathrm{MA3/4}$ & FII & EF & Feminino \\
\hline \multirow{3}{*}{$\begin{array}{l}\text { MA 19 } \\
\text { (Arari) }\end{array}$} & $\mathrm{MA} 19 / 1$ & FI & EF & Masculino \\
\cline { 2 - 5 } & $\mathrm{MA19/2}$ & FI & EF & Feminino \\
\cline { 2 - 5 } & $\mathrm{MA19/3}$ & FII & EF & Masculino \\
\cline { 2 - 5 } & $\mathrm{MA19/4}$ & FII & EF & Feminino \\
\hline
\end{tabular}

Fonte: Elaborado pelas autoras (2021)

\section{Instrumento}

Para analisarmos os dados de Pinheiro, coletados pela equipe do ALiMA, e coletarmos e analisarmos os dados da fala de moradores de Arari, considerando o contexto que se refere ao objeto de nosso estudo - realizações dos fonemas / d/ e / t / diante de [i, I] - selecionamos 18 questões das 159 que compõem o QFF do ALiMA. Justificamos a seleção dessas questões pelo fato de contemplarem perguntas que enfatizam o contexto investigado. No Quadro 2, podemos visualizar as 18 perguntas selecionadas.

Quadro 2 - Questões selecionadas do QFF adotado pelo ALiMA

\begin{tabular}{|c|c|c|}
\hline $\begin{array}{l}\text { QUES- } \\
\text { TÃO }\end{array}$ & PALAVRA & PERGUNTA \\
\hline 03 & PRA吕LLEIRA & $\begin{array}{l}\text {... aquilo assim (mímica), onde se colocam objetos em casa (latas de } \\
\text { mantimentos na cozinha, enfeites na sala...) ou produtos para vender } \\
\text { nos supermercados, mercearias, etc.? }\end{array}$ \\
\hline 06 & $\underline{\text { TESOURA }}$ & ... o objeto com que se corta tecido? \\
\hline 26 & $\begin{array}{l}\text { LIQUIDIFICA- } \\
\text { DOR }\end{array}$ & ... um aparelho que é usado para fazer vitaminas, suco, etc.? \\
\hline 30 & TOMA㺼E & $\begin{array}{l}\text {... aquilo vermelho que vende na feira e que se usa para preparar o } \\
\text { molho do macarrão? }\end{array}$ \\
\hline 49 & ELEFANTEE & $\begin{array}{l}\text {... um animal grande que sempre se vê em circo, tem uma tromba as- } \\
\text { sim (mímica)? }\end{array}$ \\
\hline 55 & NOITE & Quando fica tudo escuro e as pessoas vão dormir é a __ ? \\
\hline 56 & $\underline{\text { DIA }}$ & E depois da noite, o que é que vem? \\
\hline 62 & TARDE & Qual é o contrário de cedo? \\
\hline 69 & $\underline{\text { DESVIO }}$ & $\begin{array}{l}\text { Quando uma estrada fica interrompida por algum problema, o que é } \\
\text { que se faz ao lado para que os carros possam passar? }\end{array}$ \\
\hline 101 & ADEVGADO & $\begin{array}{l}\text { Que profissional se pode contratar para defender os interesses na Jus- } \\
\text { tiça? }\end{array}$ \\
\hline 104 & INOCENIEE & $\begin{array}{l}\text { Quando um indivíduo é acusado, mas ele não praticou aquele crime, } \\
\text { se diz que ele é o quê? }\end{array}$ \\
\hline 106 & MENIIRA & $\begin{array}{l}\text { Uma pessoa lhe conta um fato que você/ o (a) senhor (a) acha que } \\
\text { não é verdade. Você /o (a) senhor (a) diz que é uma_? }\end{array}$ \\
\hline 116 & DENTE & E isto? Apontar. \\
\hline
\end{tabular}




\begin{tabular}{|c|c|c|}
\hline 126 & $\underline{\text { DESMAIO }}$ & $\begin{array}{l}\text { Quando uma pessoa se sente mal, a vista fica turva, ela vai caindo no } \\
\text { chão, sem sentidos, o que é que se diz que ela teve? }\end{array}$ \\
\hline 131 & $\underline{\text { TIO }}$ & O que é que o irmão de seu pai ou de sua mãe é seu? \\
\hline 145 & PRESENTE & $\begin{array}{l}\text { Quando uma pessoa faz aniversário, o que é que se costuma dar a ela, } \\
\text { que vem embrulhado? }\end{array}$ \\
\hline 150 & PERDIDA & Quando não se acha uma coisa, ela fica__? \\
\hline 157 & HÓSPEDE & $\begin{array}{l}\text { Em uma pensão, um hotel, as pessoas de outros lugares que chegam } \\
\text { e ficam lá algum tempo são o quê? }\end{array}$ \\
\hline
\end{tabular}

Fonte: Elaborado pelas autoras com base nos dados do ALiMA.

\section{Tratamento dos dados}

Para a pesquisa de campo e análise dos dados, procedemos da seguinte forma: i) primeiramente, realizamos a gravação da fala dos informantes de Arari; ii) depois, realizamos a transcrição fonética e grafemática dos áudios do município de Arari; iii) quanto aos dados do município de Pinheiro, como já haviam sido coletados pela equipe do ALiMA, partimos para revisão grafemática e fonética; iv) por fim, procedemos à elaboração das cartas linguísticas ${ }^{3}$.

Para evidenciarmos as realizações dos fonemas / d/ e /t/ nos municípios de Arari e de Pinheiro, destacamos a importância de utilizarmos as cartas linguísticas para o destaque de informações dos fatores diatópico, diassexual e diageracional.

As cartas foram geradas pelo programa QGIS 3.12 Bucuresti. Com essa ferramenta apresentamos a distribuição das respostas dos informantes, para cada questão, exibidas graficamente sobre um dos mapas inseridos no software. A representação das informações é realizada por meio de gráficos de colunas. Além do mapa com os gráficos, apresentamos, ainda, as legendas de cores e porcentagens para representação dos fatores analisados.

Cabe ressaltarmos a preocupação do ALiMA com a forma adequada na condução dos inquéritos, e o rigor com os procedimentos metodológicos durante toda a coleta e transcrição dos dados, e foi com essa mesma preocupação que realizamos os inquéritos no município de Arari.

\section{Análise dos dados}

Para a organização e apresentação dos resultados - considerando as dimensões diatópica, diassexual e diagenérica -, como já dito, produzimos cartas linguísticas.

\footnotetext{
${ }^{3}$ Utilizamos o termo carta linguística para nos referir aos dados linguísticos representados em um mapa geográfico.
} 


\section{Dimensão diatópica}

Primeiramente, é importante frisarmos que variação diatópica (ou geográfica) diz respeito à relação da identidade e da cultura de diferentes comunidades de fala situadas em diferentes espaços geográficos, o que nos possibilita o reconhecimento de que determinado falante se distingue de outros falantes justamente por pertencer à determinada comunidade e não a uma outra.

Nesse contexto, na Carta 1, apresentamos os resultados referentes à não palatalização e à palatalização nos municípios de Arari e Pinheiro.

Carta 1 - Carta sobre Não palatalização x Palatalização (localidades)

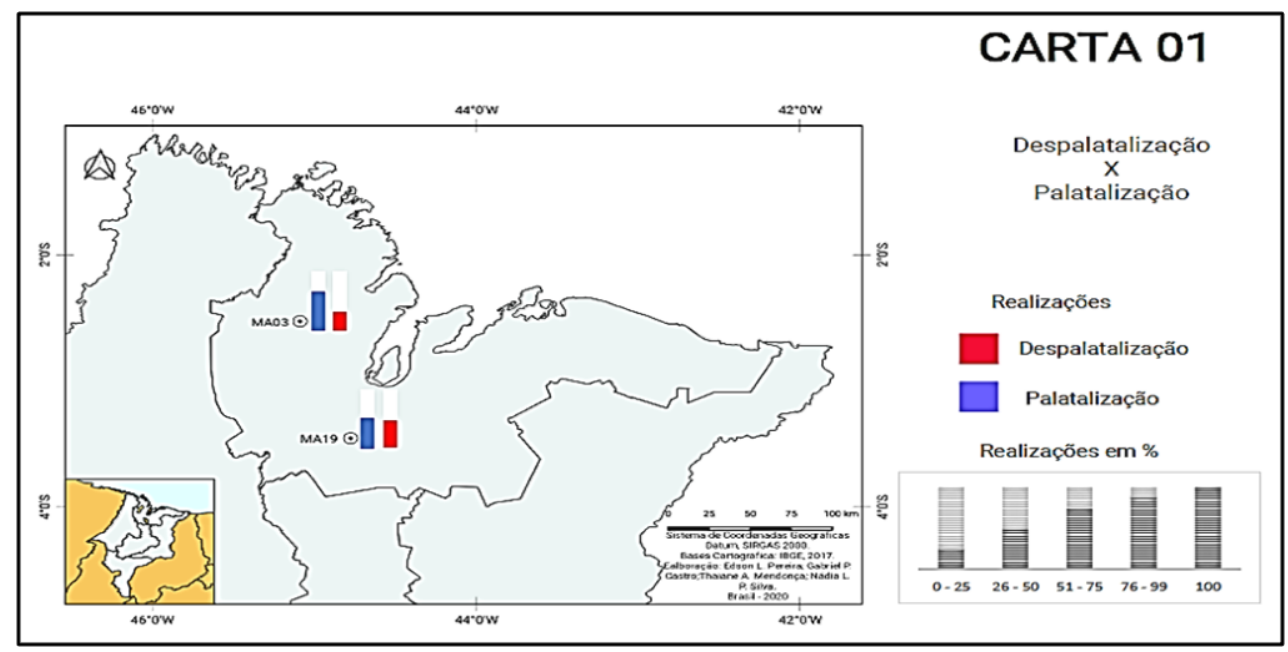

Fonte: Elaborada pelas autoras (2021)

Verificamos que das 144 realizações, 76 configuraram a palatalização dos fonemas /d/ e /t/, o que representou um percentual de $52 \%$, contra 53 ocorrências de não palatalização dos fonemas em questão, o que totalizou $48 \%$.

Destacamos que tivemos 15 respostas que não se aplicaram nem à palatalização nem à não palatalização, ou porque os informantes não deram a resposta esperada, não lembraram ou porque não souberam responder, consequentemente, essas 15 respostas dadas não apareceram na Carta 1.

Segue o Quadro 3 com o resumo das informações dos dados analisados incluindo os casos não lembra, não obtida e não sabe, representados, respectivamente, pelas siglas N.L, N.O e N.S. 
Quadro 3 - Resumo da análise dos dados obtidos com as questões do QFF

\begin{tabular}{|l|l|l|l|}
\hline \multirow{2}{*}{ VARIANTES } & \multicolumn{2}{|c|}{ LOCALIDADES } & \multirow{2}{*}{ TOTAL } \\
\cline { 2 - 4 } & PINHEIRO (MA03) & ARARI (MA19) & \\
\hline Palatalização & 40 & 36 & 76 \\
\hline Não palatalização & 20 & 33 & 53 \\
\hline N.L & 01 & - & 01 \\
\hline N.O & 11 & 02 & 13 \\
\hline N.S & - & 01 & 01 \\
\hline
\end{tabular}

Os dados mostram que a propalada realização não palatalizada dos fonemas / d/ e /t/ diante de $[\mathrm{i}, \mathrm{I}]$ na fala de maranhenses naturais dos municípios que representaram a Baixada Maranhense neste estudo, já não é tão recorrente quanto historicamente divulgada entre os maranhenses. Como o objetivo geral deste trabalho foi investigar a não palatalização dos fonemas /d/ e / t / diante [i, I] nos municípios maranhenses de Arari e de Pinheiro, verificamos, com base nos dados analisados, que há, no momento, uma diminuição da realização não palatalizada dos fonemas investigados em relação ao que se propagava historicamente nesses dois municípios, o que nos faz pensar na probabilidade de que, no futuro, a variante não palatalizada deixe de ser realizada, uma vez que a variante palatalizada obteve mais de $50 \%$ de realizações.

Com o intuito de refinar a nossa análise sobre a não palatalização, destacamos ainda, na Carta 1, que Arari é o município onde mais ocorre a não palatalização nos contextos investigados neste estudo. Desse modo, das 53 realizações encontradas na fala dos informantes de Arari e Pinheiro, 33 foram realizadas por informantes do município de Arari, representando o percentual de $62 \%$, ao passo que, em Pinheiro, tivemos apenas 20 realizações, o que corresponde a um percentual de $38 \%$.

\section{Dimensão diassexual}

No que diz respeito à dimensão diassexual, a Carta 2 apresenta o resultado das análises sobre o sexo dos informantes dos municípios de Arari e Pinheiro quanto à realização da não palatalização. 
Carta 2 - Carta diassexual

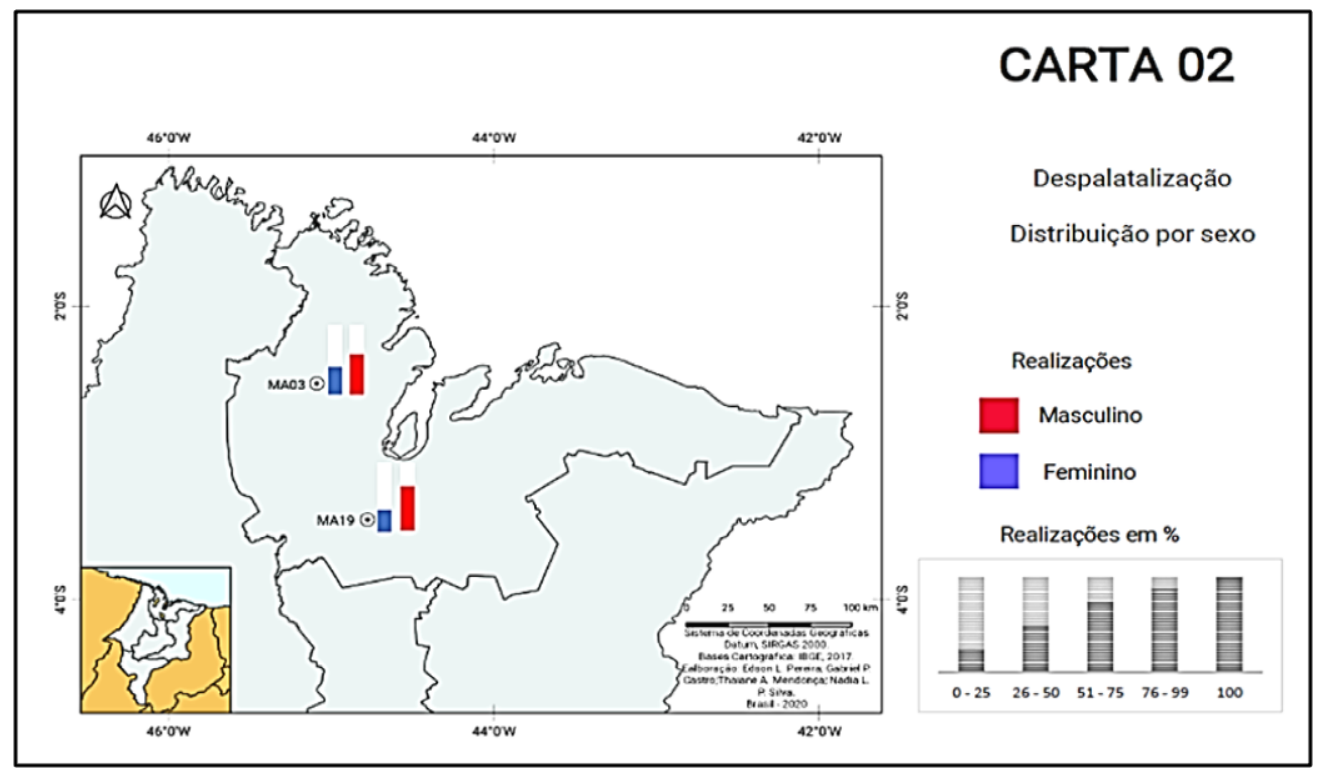

Fonte: Elaborada pelas autoras (2021)

Procedendo às análises, verificamos que, de acordo com a Carta 2, quanto ao fator diassexual, os informantes do sexo masculino tenderam a fazer mais uso da variante não palatalizada nos dois municípios alvos de nossa investigação, ao passo que os informantes do sexo feminino utilizaram mais a variante palatalizada. Podemos melhor ratificar essa evidência quando analisamos esse fator por localidade. Observemos, por exemplo, a localidade de Arari, em que das 33 realizações não palatalizadas, 22 foram feitas por informantes do sexo masculino, perfazendo um percentual de $67 \%$, e apenas 11 casos de não palatalização foram realizados por informantes do sexo feminino, cujo percentual foi de $33 \%$. Para melhor visualização desses dados, apresentamos o Quadro 4. Os números representam a quantidade de realizações das variantes.

Quadro 4: Resultado referente ao fator diassexual obtido com as questões do QFF

\begin{tabular}{|l|l|c|c|c|}
\hline \multirow{2}{*}{ LOCALIDADES } & \multirow{2}{*}{ VARIANTE } & \multicolumn{2}{|c|}{ SEXO } & \multirow{2}{*}{ TOTAL } \\
\cline { 3 - 5 } & & MASCULINO & \multirow{2}{*}{ FEMININO } & \\
\hline \multirow{2}{*}{$\begin{array}{l}\text { PINHEIRO } \\
\text { MA03 }\end{array}$} & Não palatalização & 12 & 08 & $\mathbf{2 0}$ \\
\cline { 2 - 5 } & Palatalização & 15 & 25 & $\mathbf{4 0}$ \\
\hline ARARI & Não palatalização & 22 & 11 & $\mathbf{3 3}$ \\
\cline { 2 - 5 } & Palatalização & 11 & 25 & \multicolumn{3}{|c|}{ Fonte: Elaborado pelas autoras (2021) } \\
\hline
\end{tabular}

Sendo assim, os nossos resultados contrariam o defendido por Oliveira e Silva (1998) ao afirmarem que em situações de mudança que compreendem processos de prática de uma 
variante não-padrão ${ }^{4}$, as mulheres preferem as formas conservadoras enquanto os homens comandam o processo. Em nosso estudo, de acordo com os dados, percebemos uma situação contrária, isto é, os homens estiveram na vanguarda da variante tida como padrão.

\section{Dimensão diageracional}

A Carta 3 apresenta o resultado das análises referentes às faixas etárias I e II dos informantes dos municípios de Arari e Pinheiro quanto à não palatalização.

Carta 3 - Carta diageracional

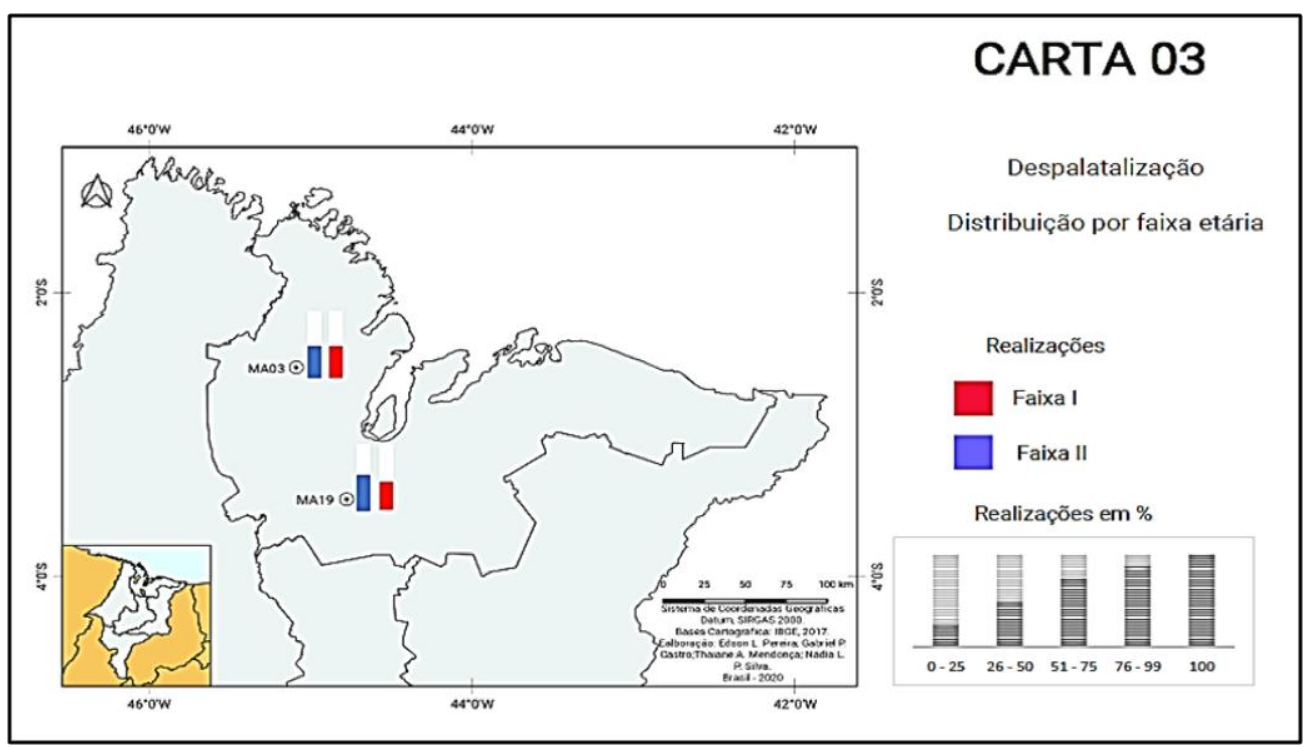

Fonte: Elaborada pelas autoras (2021)

Quanto ao fator diageracional, de acordo com a Carta 3, verificamos que os informantes da faixa etária II tendem a fazer mais uso da variante não palatalizada. Pudemos verificar isso mais nitidamente no município de Arari onde, das 33 realizações despalatalizadas, 18 foram da faixa etária II, o que representa um percentual de 55\%; ao passo que os da faixa etária I, nesse município, estiveram mais voltados à utilização da variante palatalizada, com 20 realizações, o que correspondeu a 56\%. No município de Pinheiro, as faixas etárias aparecem com a quantidade de ocorrência similar: das 20 realizações não palatalizadas, 10 foram na faixa etária I e 10, na faixa etária II.

Esses números indicam que a variante não palatalizada, apesar de ser menos utilizada que a variante palatalizada, nos municípios de Arari e Pinheiro, conforme Quadro 5, ainda é a mais empregada pelos falantes da faixa etária II no município de Arari, e a menos aceita

\footnotetext{
${ }^{4}$ Para nosso trabalho, a variante tida como não-padrão nos municípios de Arari e Pinheiro é a palatalização.
} 
pelos falantes da faixa etária I desse município, o que corrobora a ideia defendida por Tarallo (2002, p. 65-66): "Para atestar a mudança em progresso [...] é necessário que as variantes sejam correlacionadas aos diversos grupos etários: maior incidência nas faixas mais jovens e menor frequência nas mais velhas.”.

Quadro 5 - Resultado referente ao fator diagenérico obtido com as questões do QFF

\begin{tabular}{|l|c|c|c|c|}
\hline \multirow{3}{*}{ LOCALIDADES } & \multirow{3}{*}{ VARIANTE } & \multicolumn{2}{|c|}{ FAIXA ETÁRIA } & \multirow{2}{*}{ TOTAL } \\
\cline { 3 - 4 } & & FAIXA & FAIXA & \\
\hline \multirow{2}{*}{$\begin{array}{l}\text { PINHEIRO } \\
\text { MA03 }\end{array}$} & Não palatalização & 10 & 10 & $\mathbf{2 0}$ \\
\cline { 2 - 4 } $\begin{array}{l}\text { ARARI } \\
\text { MA19 }\end{array}$ & Palatalização & 22 & 18 & $\mathbf{4 0}$ \\
\cline { 2 - 5 } & Não palatalização & 15 & 18 & $\mathbf{3 3}$ \\
\hline
\end{tabular}

Fonte: Elaborado pelas autoras (2021)

As análises realizadas apontam para uma mudança em tempo aparente, pois a conclusão geral é a de que falantes jovens palatalizam mais do que falantes mais velhos, o que sugere que a variante palatalizada tende a progredir nas comunidades dos municípios de Arari e Pinheiro, já que a tendência natural é que a variante não palatalizada deixe de ser empregada com o passar dos anos por ser mais utilizada por pessoas mais idosas.

\section{Considerações finais}

Algumas variantes linguísticas nem sempre são bem aceitas por uma parcela da sociedade e, infelizmente, atitudes discriminatórias acontecem, o que corrobora o chamado preconceito linguístico. Nesse contexto, o fenômeno da não palatalização é um dos alvos desse preconceito, pois, muitas vezes, não é entendido como riqueza e diversidade cultural, tornando-se alvo de estigmatização.

Bagno (1999) destaca a necessidade de estudos científicos e de uma abordagem educacional em favor de uma educação linguística voltada para a inclusão social e para o reconhecimento e valorização da diversidade cultural brasileira. Enfatizamos, nesse sentido, que trabalhos como este, além de contribuir para o entendimento de fenômenos linguísticos do português maranhense/brasileiro, podem ajudar a esclarecer melhor as realizações da língua e a diminuir a visão errônea que muitos falantes têm sobre a variação linguística.

Em relação à análise que foi realizada neste trabalho, à luz da Dialetologia e da Geolinguística, constatamos que os fatores extralinguísticos exerceram influência na não palatalização/palatalização dos fonemas /d/ e /t/ nos municípios de Arari e Pinheiro, no estado do Maranhão. Desse modo, chegamos às seguintes conclusões: a) quanto às localidades investigadas, Arari foi o município em que mais ocorreu a não palatalização; b) quanto ao fator 
diassexual, os informantes do sexo masculino, em ambos os municípios, utilizaram mais a variante não palatalizada do que os informantes do sexo feminino; c) quanto ao fator diageracional, os informantes mais idosos, dos dois municípios investigados, foram os que mais utilizaram a variante não palatalizada.

Assim, concluímos que a não palatalização dos fonemas /d/ e / t / diante de [i, I], nos município de Arari e Pinheiro, é um fenômeno variável. Após análise dos dados, os resultados nos permitiram inferir que a regra variável de não palatalização parece estar sendo mais produzida entre os falantes do sexo masculino e da faixa etária II, o que nos dá amostras de uma possível diminuição e, posteriormente, extinção dessa variante em questão, pois são os falantes mais jovens, da faixa etária I, que parecem conduzir a variante palatalizada nas localidades.

\section{REALIZATION OF THE PHONEMES / d / E / $\mathrm{t}$ / IN THE CITIES OF ARARI AND PIN- HEIRO: A GEOLINGUISTIC APPROACH}

ABSTRACT: This study aimed to investigate the realizations of the phonemes / d / and / $\mathrm{t} /$ preceding $[\mathrm{i}, \mathrm{I}]$ in the cities of Arari and Pinheiro, located in the Brazilian State of Maranhão, aiming to ratify the non-palatalization that, historically, particularizes the Portuguese spoken in these cities. The research was based on Aguilera; Altino, 2012, Aragão, 2018, Cagliari, 1974, Cardoso, 2010, Silva, 2002. Field research was carried out for data collection, phonetic and graphical transcription, preparation of linguistic letters, data analysis. The analysis pointed out that non-palatalization, in these locations, is no longer as recurrent as has been said historically.

KEYWORDS: Geolinguistic; Non-palatalization; Phonemes.

\section{REFERÊNCIAS}

AgUILERA, Vanderci de Andrade; ALTINO, Fabiane Cristina. Para um Atlas Pluridimensional: pesquisas e pesquisadores. Alfa: São Paulo, 2012.

ARAGÃO, Maria do Socorro Silva de. A despalatizaçãa e consequente iotização no falar de fortaleza. PROFALA: UFC, 2018.

BAGNO, M. Preconceito lingüistico: o que é, como se faz. São Paulo: Loyola, 1999.

BERGO, Vitorio. Pequeno dicionário brasileiro de gramática portuguesa. Rio de Janeiro: Francisco Alves, 1986.

BIBLIOTECA ONLINE-IBGE/AS. Disponível em: https://biblioteca.ibge.gov.br/. Acesso em: 27 de julho de 2020.

CAGLIARI, Luís Carlos. A palatização em português: uma investigação palatográfica. Dissertação de mestrado. São Paulo, Campinas: UNICAMP, 1974.

CARDOSO, Manoel Frazão. O Maranbão por dentro. São Luís: LITHOGRAF, 2001.

CARDOSO, Suzana Alice. O Atlas lingüistico do Brasil: uma questão política. Seminário Nacional Caminhos e Perspectivas para a Geolinguística no Brasil. Salvador. Atas... Salvador: Serviço de Reprografia da Pró-Reitoria de Planejamento da UFBA, 1997. 
CARDOSO, Suzana Alice. Geolinguística: tradição e modernidade. São Paulo: Parábola Editorial, 2010.

"Dialetologia”. In: Mollica; M. C.; Ferrarezi JR., C. (Orgs.). Sociolinguistica, sociolinguísticas: uma introdução. São Paulo: Contexto, 2016.

COSERIU, E. A geografia lingüistica. In: COSERIU, E. El hombre y su lenguaje. Tradução de Carlos A. da Fonseca; Mário Ferreira. Rio de Janeiro: Presença, 1987.

COSTA, Geisa Borges de. Da música regional como fonte de pesquisa dialectológica: o português rural na música de Elomar. Revista de divulgação científica em Língua Portuguesa: Letras Magna, 2012.

SILVA, Thais Cristófaro. Fonética e Fonologia do Português: roteiro de estudos e guia de exercícios. São Paulo: Contexto, 2002.

DUBOIS, Jean et al. Dicionário de lingüística. São Paulo: Cultrix, 1978.

ILARI, R.; BASSO, R. O português da gente: a língua que estudamos, a língua que falamos. 1.ed. São Paulo: Contexto, 2007.

LOPES, E. Fundamentos da Linguística Contemporânea. 20. ed. São Paulo: Cultrix, 2001.

MOTA, J. A.; CARDOSO, S. A. M. Sobre a Dialetologia no Brasil. In.: MOTA, J.

A.; CARDOSO, S. A. M. Documentos 2: Projeto Atlas Linguístico do Brasil. Salvador: Quarteto, 2006, p. 15-34.

OLIVEIRA E SILVA, G. M. Variáveis sociais e perfil do corpus censo. In: OLIVEIRA E SILVA, Scherre; PEREIRA, Maria Marta (Orgs.). Padrões sociolinguísticos. 2.ed. UFRJ, 1998.

PREFEITURA DE ARARI. Aspectos gerais do município de Arari. 2017. Disponível em: $<$ https: / www.arari.ma.gov.br/index.php?option $=$ com_content\&view $=$ article\&id $=74>$. Acesso em: 08 de agosto de 2020.

RAMOS, C. M. A. (Coord.). Projeto Atlas Linguístico do Maranbão. São Luís: Universidade Federal do Maranhão. (Departamento de Letras). 82p. 2005.

ROMANO, V. P. Balanço crítico da Geolinguística brasileira e a proposição de uma divisão. Entretextos: Londrina, 2013.

TARALLO, F. A pesquisa sociolinguística. São Paulo: Ática, 2002.

Recebido em: 30/04/2021.

Aprovado em: 12/06/2021. 